\title{
Smartphone app-based interventions to support smoking cessation in smokers with mental health conditions: A systematic review
}

\author{
Jinsong Chen ( $\nabla_{\text {jinsong.chen@auckland.ac.nz })}$ \\ University of Auckland https://orcid.org/0000-0002-1833-7133 \\ Joanna Ting Wai Chu \\ The University of Auckland National Institute for Health Innovation \\ Samantha Marsh \\ The University of Auckland National Institute for Health Innovation \\ Chris Bullen \\ The University of Auckland National Institute for Health Innovation
}

\author{
Research \\ Keywords: smoking cessation, mobile health, mental health \\ Posted Date: April 8th, 2021 \\ DOI: https://doi.org/10.21203/rs.3.rs-401435/v1 \\ License: () (1) This work is licensed under a Creative Commons Attribution 4.0 International License. Read Full License
}




\section{Abstract}

Background: Despite decades of global tobacco control efforts, tobacco smoking remains a leading cause of preventable disease, death and inequality. Smoking is particularly common in people with mental health conditions. Smartphone apps have been developed as an accessible and affordable tool to support smokers with mental health conditions to quit smoking. However, limited data exists regarding the extent to which these apps are underpinned by evidence from research.

Methods: We searched for apps designed to assist smokers with mental health conditions to quit smoking, in two ways: one, from the scientific literature, and two, directly from app stores. For the apps found in app store searches, we determined the extent to which they drew on theories or empirical research evidence for their design, their features, and claims of effectiveness. We assessed and compared usage and rating scores for all apps.

Results: The literature search identified eight articles with five apps that were developed based on theories or empirical research evidence. Only two of these apps were available from an app store. Conversely, among the 22 apps found in the major app stores, only nine (41\%) were built using theories or research evidence. All apps identified from app stores achieved far larger user numbers (minimum download rate $=1,000$ times) and higher user rating scores (average 4.7 out of 5.0) than the apps identified in the literature search (user rating scores average 3.75).

Conclusions: In general, smokers with mental health conditions are poorly served by available smoking cessation apps. Most apps developed using theories or empirical evidence are poorly used and have limited longevity. Researchers should plan for ongoing support of research-based apps, beyond the life of the research project. Developers should work in collaboration with researchers to build apps that combine theory and evidence with more engaging end-user design features.

\section{Background}

Tobacco smoking is a leading cause of preventable death in the world [1]. Although millions of smokers receive advice from their healthcare providers each year for quitting smoking, and over half of them attempt to quit, the success rate is low [2]. Without any support, the success rate from a quit attempt is about $5 \%$ to $7 \%$ [3], but it can be raised to over $20 \%$ with behavioural intervention even without pharmacotherapy $[4,5]$. Unfortunately, $85 \%$ of tobacco users in the world have no access to cessation support [6].

Mental health conditions and smoking are strongly correlated; people with mental health conditions are far more likely to smoke tobacco than those without mental health conditions, and smoking amplifies the negative impacts of their medication and physical co-morbidities on their mental wellbeing [7-10]. Nevertheless, there is good evidence that smokers with mental health issues are just as interested in and able to quit smoking as others, even more so when support is provided [7-10]. For this reason, people with mental illness and other addictions often carry a greater burden of disease due to smoking. Poor lung health, smoking and poor mental health co-occur: $50 \%$ of chronic obstructive pulmonary disease (COPD) patients have depressive symptoms, and over one in five COPD patients experience anxiety [7, 11, 12]. Smokers are more likely to develop depressive symptoms than non-smokers [13]. Smokers with mental health issues are also more likely to (1) keep on smoking; (2) consume more tobacco products; (3) die on average 10 to 20 years earlier; and (4) need higher doses of antipsychotic medicines and antidepressants [13]. Smoking also increases socioeconomic and ethnic disparities [7, 11-13]. However, by quitting smoking, people may experience a reduction in anxiety, depression and stress levels; improvements in quality of life and mood; and decreases in use of mental health medicines $[7,11-13]$.

The most recent Cochrane Review found moderate-certainty evidence, limited by inconsistency, that mobile smoking cessation (text message-based) interventions were more effective than minimal smoking cessation support (risk ratio [RR] $=1.54,95 \% \mathrm{Cl}=1.19$ to $2.00 ; 13$ studies, 14,133 participants) [14]. There was also moderate-certainty evidence, limited by imprecision, that text messaging added to other smoking cessation interventions was more effective than the other smoking cessation interventions alone ( $\mathrm{RR}=1.59,95 \% \mathrm{Cl}=1.09$ to 2.33; 4 studies, 997 participants) [14]. Compared to traditional in-person interventions, mobile smoking cessation interventions have been shown to improve user engagement with a cessation programme by expanding communication through real-time messaging with support networks, and by reducing barriers to access such as cost, location, or timing conflicts [15-17]

However, text-based programmes have limited functionality, whereas smartphone apps offer more interactive and customisable tools to support smokers throughout the multi-stage process of quitting smoking, such as tools for self-monitoring, progress tracking, urges overcoming, daily reminders and social support [18]. A growing number of apps purporting to be effective at helping smokers quit are available for downloading [19-67].

In recent years, apps have been developed to support individuals with mental health issues to quit smoking [46, 68, 69]. Research suggests that smoking cessation apps can engage smokers with mental health issues, [28] including those who are not already receiving nor seeking professional help [68], and may promote smoking cessation or reduction of tobacco consumption [69], and improve mental health status [46]. With the proliferation of smartphones, mobile health tools are uniquely positioned to reach and influence the smoking populations that need both smoking cessation and mental health support [70]. However, there has been little assessment of the quality of content, engagement and reach of apps that are underpinned by research or theory, compared with apps commonly used in the marketplace [46, 59-69] that purport to assist smokers with mental health issues to quit [71, 72].

\section{Objective}

The aim of this review was to identify available apps designed to support smoking cessation of smokers with mental health conditions, identify apps developed from theory and/or empirical scientific evidence, with apps without such as basis, available from app stores and to determine and compare the usage, user ratings and availability of such apps.

\section{Methods}


To achieve this goal, the app market was evaluated from two perspectives: one, the health professional perspective; and two, the consumer (smokers with mental health conditions) perspective. Health professionals are more likely than consumers to review the scientific literature. Without access to research literature, consumers are likely to rely on the recommendations of app stores when selecting healthcare apps. Exploration from this dual perspective required us to review the apps in two ways: one, starting from the literature and finding identified apps in the app stores and two, starting from the app stores.

To remain consistent with other published systematic reviews of smoking cessation apps [71-75], we followed the Preferred Reporting Items for Systematic Reviews and Meta-Analyses (PRISMA) model, and evidence-based set of criteria for reporting in systematic reviews and meta-analyses [76]. Many smoking cessation apps provide support grounded in valid, evidence-based behaviour change strategies (i.e., taxonomy of behaviour change techniques) while never being reported in a published research article. The aim of this review was to start by identifying the smoking cessation apps identified by the scientific community and recommended for consumer use to form a foundation of scientifically supported apps for smokers with mental health conditions. We elected to evaluate apps in line with traditional health interventions, which looks to the published medical literature for guidance. Therefore, for this review, only published research articles related to smoking cessation apps for smokers with mental health conditions were considered evidence of scientific support. Apps designed to facilitate smoking cessation among smokers with mental health conditions were identified and evaluated in four steps.

Step 1: Identify all smoking cessation apps for smokers with mental health conditions reported in the scientific literature

We did a literature search of EMBASE, MEDLINE, APA PsycInfo, PubMed, Scopus, ACM Digital Library, and IEEE Xplore on $30^{\text {th }}$ September 2020. Table One shows the search terms used in different fields of the study. Because search engines differ between databases, search strategies were adapted to each database. Appendix 1 shows the search strategies used in the different databases. Only peer-reviewed articles on the topic of smoking cessation apps for smokers with mental health conditions that were published in English before the search date were included for the review.

Table 1: Search terms used

\begin{tabular}{|ll|}
\hline Fields & Terms \\
\hline Smoking & $\begin{array}{l}\text { Smoking OR "smoking cessation" OR "quit smoking" OR "stop smoking" OR cigarette OR "cigarette cessation" OR tobacco OR "tobacco } \\
\text { cessation." }\end{array}$ \\
\hline App & $\begin{array}{l}\text { App* OR application OR "mobile app*" OR "mobile software" OR "mobile program*" OR "smartphone app*" OR "smartphone software" OR } \\
\text { "smartphone program*." }\end{array}$ \\
\hline $\begin{array}{l}\text { Mental } \\
\text { Health }\end{array}$ & \begin{tabular}{l} 
Anxiety OR depression OR stress OR emotion* OR mental OR "mental health" OR "mental health wellbeing" OR "mental disorder*" OR \\
\hline
\end{tabular} \\
\hline
\end{tabular}

A data extraction sheet based on the review of mobile phone-based interventions for smoking cessation published in the Cochrane Database of Systematic Reviews [77] was developed to collect data from the identified articles. The data extraction sheet was adapted by adding a field on the impact of the intervention on the mental health statuses of users. One review author (JChe) from the team extracted the data, and the other authors (CB, JC, SM) checked the data. Disagreements were resolved by consensus. Information included (1) information about the study (including country and year of the study's implementation); (2) characteristics of the app (including the name of the app, underpinning theories, app development methods, functions, and target users); (3) evaluation of the app (including the assessment method, interventions, participants, duration, types of measure, findings, bias, and limitations).

No gold standard exists against which to evaluate a smoking cessation app for smokers with mental health conditions. A meta-analysis of study findings was, therefore, not possible. Hence, identified literature was analysed by identifying availability, validity, user experience, and effectiveness of current smoking cessation apps for mental health smokers. Analysis of the features of current apps, their potential for improvement, and the feasibility of evaluation to validate these apps' effectiveness and acceptability was also included.

We assessed risk of bias and obtained methodological details using a standardised form applied by a Cochrane Review on mobile smoking cessation interventions [77]. Different types of bias were assessed across studies including (1) selection bias - whether study participants are representative to the target population; (2) performance bias and detection bias - whether any types of blinding were performed; (3) attrition bias - incomplete outcome or loss of follow up; (4) other bias - specified as small sample size, short follow up, and confounding factors. Each type of bias was rated for each study by JChe with one of the following three risk levels: "high risk"; "low risk", and "unclear". The results of the rating were reviewed by other authors (CB, JC and SM) and agreement was reached between authors.

Step 2: Identify the apps from the literature review available in the app stores

Each app identified in the scientific literature during phase 1 was searched for in each of the following online app stores: the Apple App Store and the Google Play Store. Apps with the same name and developer of those listed in the literature were considered a match. Functions of smoking cessation apps were classified based on the taxonomy created by the National Tobacco Cessation Collaboration (NTCC) [78] and its updated version of the classification method developed by Abroms et al. [73].

Phase 3: Identify the top smoking cessation apps for smokers with mental health conditions, smoking cessation apps, and mental health apps available in app stores 
We searched the two main online app stores (Apple App Store and the Google Play Store) in January 2021 using the following terms: mental health smoking, mental health, and quit smoking. Each search term was searched separately and all three were used for each of the two stores, totalling six separate searches. The top five apps returned per search were documented for each store. Apps not relevant to the support of smoking cessation or improving of users' mental health status were removed.

\section{Step 4: Identify the apps from the app stores developed from theory or empirical evidence.}

The top five apps per search term were opened and reviewed regarding their developers, theories, development methods, smoking cessation features, mental health features, target users, categorises, charge, download rate, and user rating. Description (both in app stores and in "About" section of the apps) of the apps was reviewed to determine if the reviewed apps were developed based on theories. An app with explicit theory or theory-related functions or components mentioned in its description was considered as theory-based. Apps that had been tested in a methodologically robust way were considered as based on

empirical evidence. Only the top five apps were chosen to best represent real search behaviours of focusing on the top apps of search results, which is unlikely to include all apps available for the given health concerns $[79,80]$. An app list was created by one review author (JChe) and shared with the other review authors (CB, JC and SM). All authors reviewed and analysed apps independently and discussed the key findings of the analysis.

\section{Results}

Step 1: The search of listed databases provided a total of 1989 articles. After adjusting publication types and written languages, 447 articles remained. Of these, 349 articles were discarded because after reviewing the abstracts, these articles did not meet the inclusion criteria. By the end of title and abstract review, 98 articles were imported into the Endnote reference management system, where 28 duplicate articles were identified and excluded. The full text of the remaining articles was examined in detail. Sixty-one studies did not meet the inclusion criteria as described leaving only eight studies in the systematic literature review. No additional studies were identified by checking the references of located, relevant papers and searching for studies that have been cited by included studies. No unpublished studies were obtained. The flow diagram of articles selection is shown in Figure 1. The following table (Table 2) summarises the details of the reviewed studies.

Table 2: Details of the Reviewed Studies 


\begin{tabular}{|c|c|c|c|}
\hline Source & $\begin{array}{l}\text { Study Design } \\
\text { Participant }\end{array}$ & Interventions and Follow-up & Outcomes and Measures \\
\hline $\begin{array}{l}\text { Hertzberg } \\
\text { et al. } \\
2013[81]\end{array}$ & $\begin{array}{l}\text { Pilot RCT } \\
\text { Smokers with PTSD }(n=22)\end{array}$ & $\begin{array}{l}\text { Intervention: } \mathrm{mCM}(\mathrm{app}) \text { and two smoking cessation } \\
\text { counselling sessions, nicotine replacement, and bupropion } \\
(\mathrm{n}=11) \\
\text { Control: non-app conditions }(\mathrm{n}=11) \\
\text { Follow-up: Three months }\end{array}$ & $\begin{array}{l}\text { Adherence: Compliance with trial } \\
\text { activities } \\
\text { Smoking status: CO-verified 7-day PPA at } \\
\text { 4-week and 3-month follow-up }\end{array}$ \\
\hline $\begin{array}{l}\text { Vilardaga } \\
\text { et al. } \\
2016 \text { [82] }\end{array}$ & $\begin{array}{l}\text { Qualitative study } \\
\text { Individuals with a history of } \\
\text { serious mental illness }(n=5)\end{array}$ & $\begin{array}{l}\text { Day 1: introduced participants to QuitPal (app) with a brief } \\
\text { hands-on demonstration and explain its functions } \\
\text { Day 2-3: participants field-tested QuitPal and interacted with } \\
\text { the app to gain a more in-depth user experience } \\
\text { Follow-up: Three days }\end{array}$ & $\begin{array}{l}\text { Adherence: App usage logs } \\
\text { User experience: Interview and SUS } \\
\text { questionnaire }\end{array}$ \\
\hline $\begin{array}{l}\text { Hicks et } \\
\text { al. } 2017 \\
{[83]}\end{array}$ & $\begin{array}{l}\text { Pilot RCT } \\
\text { Smokers with PTSD }(n=11)\end{array}$ & $\begin{array}{l}\text { Intervention: QUIT4EVER, an intervention combining mobile } \\
\text { contingency management smoking cessation counselling } \\
\text { and medications, and the SCQ app }(n=5) \\
\text { Control: a contact control condition that was identical to } \\
\text { QUIT4EVER except SCQ app was not included }(n=6) \\
\text { Follow-up: Six months }\end{array}$ & $\begin{array}{l}\text { Smoking status: Self-reported prolonged } \\
\text { smoking abstinence } \\
\text { User experience: Perceived effectiveness } \\
\text { on a Likert scale questionnaire }\end{array}$ \\
\hline $\begin{array}{l}\text { Minami } \\
\text { et al. } \\
2018 \text { [69] }\end{array}$ & $\begin{array}{l}\text { Pilot trial } \\
\text { Smokers with psychiatric } \\
\text { disorders (have a depressive } \\
\text { disorder or bipolar disorder) } \\
(\mathrm{n}=8)\end{array}$ & $\begin{array}{l}\text { A smartphone intervention app that prompts participants to } \\
\text { practice mindfulness (listening to an audio recording on the } \\
\text { smartphone five times per day), complete EMA reports five } \\
\text { times per day, and submit CO videos twice per day } \\
\text { Follow-up: Three months }\end{array}$ & $\begin{array}{l}\text { Adherence: Compliance with trial } \\
\text { activities } \\
\text { Smoking status: CO-verified 7-day PPA at } \\
\text { 2-, 4-week, and 3-month post-quit follow- } \\
\text { ups, and Cigarettes use reduction } \\
\text { User experience: Satisfaction to the } \\
\text { programme questionnaire }\end{array}$ \\
\hline $\begin{array}{l}\text { Heffner } \\
\text { et al. } \\
2019 \text { [84] }\end{array}$ & $\begin{array}{l}\text { Pilot trial } \\
\text { Daily smokers with mild to } \\
\text { moderate depressive symptoms } \\
(n=16)\end{array}$ & $\begin{array}{l}\text { Smokefree TXT along with Actify! (app) to provide cessation } \\
\text { content that had not yet been built into the app for this pilot } \\
\text { testing } \\
\text { Follow-up: Six weeks }\end{array}$ & $\begin{array}{l}\text { Adherence: Number of log-ins per } \\
\text { participants and reported usability } \\
\text { challenges } \\
\text { Mental health status: Depressive } \\
\text { symptoms measured by the PHQ } \\
\text { Smoking status: CO-verified, 7-day and } \\
\text { 30-day PPA at 6-week follow-up } \\
\text { User experience: Interview }\end{array}$ \\
\hline $\begin{array}{l}\text { Herbst et } \\
\text { al. } 2019 \\
\text { [68] }\end{array}$ & $\begin{array}{l}\text { Qualitative study } \\
\text { US military veterans with PTSD } \\
\text { who smoked at least five } \\
\text { cigarettes per day for } 15 \text { of the } \\
\text { past } 30 \text { days and stated an } \\
\text { interested in cessation }(n=20)\end{array}$ & $\begin{array}{l}\text { Use of the SQC app } \\
\text { Follow-up: Three months }\end{array}$ & $\begin{array}{l}\text { Adherence: Retention } \\
\text { User experience: Comfort levels with } \\
\text { mobile technology (baseline measure) - } \\
\text { the PMPIQ-P and Interview }\end{array}$ \\
\hline $\begin{array}{l}\text { Wilson et } \\
\text { al. 2019 } \\
\text { [85] }\end{array}$ & $\begin{array}{l}\text { Qualitative study } \\
\text { Smokers with schizophrenia, } \\
\text { schizoaffective, or psychotic } \\
\text { disorders) two cohorts (Cohort } 1 \\
n=5 \text {, Cohort } 2 n=8 \text {, total } n=13 \text { ) } \\
\text { Therapists }(n=2)\end{array}$ & $\begin{array}{l}\text { The intervention included mobile contingency management } \\
\text { (i.e., financial compensation for confirmed abstinence from } \\
\text { smoking), pharmacotherapy for smoking cessation, } \\
\text { cognitive- behavioural counselling sessions, and the use of } \\
\text { SQC app for relapse prevention } \\
\text { Follow-up: Three months }\end{array}$ & $\begin{array}{l}\text { Adherence: Compliance with treatment } \\
\text { Smoking status: Self-reported smoking } \\
\text { abstinence } \\
\text { User experience: Interview Perception of } \\
\text { usefulness }\end{array}$ \\
\hline $\begin{array}{l}\text { Alyssa et } \\
\text { al. } 2020 \\
{[86]}\end{array}$ & $\begin{array}{l}\text { RCT } \\
\text { Smokers with diagnosed mental } \\
\text { health illness }(n=34)\end{array}$ & $\begin{array}{l}\text { Intervention: mobile CM (i.e. monetary compensation for bio- } \\
\text { verification of abstinence through using a phone app), CBT, } \\
\text { and pharmacotherapy for smoking cessation }(n=21) \\
\text { Control: ITC, which contained all components except the CM } \\
(n=13) \\
\text { Follow-up: Six months }\end{array}$ & $\begin{array}{l}\text { Acceptability: A questionnaire assessing } \\
\text { eight self-reported items } \\
\text { Feasibility: A questionnaire that was } \\
\text { completed by the therapist about the } \\
\text { participant } \\
\text { Knowledge of treatment: A tailored } \\
\text { questionnaire } \\
\text { Smoking status: Self-reported prolonged } \\
\text { abstinence, Bio-verified (including saliva } \\
\text { and CO verification) prolonged } \\
\text { abstinence at } 6 \text {-month follow-up, 7-day } \\
\text { and } 30 \text {-day self-reported PPA }\end{array}$ \\
\hline
\end{tabular}

SUS: System Usability Scale

PPA: Point Prevalence Abstinence 
PTSD: Post-Traumatic Stress Disorder

PMPIQ-P: Perceptions of Mobile Phone Interventions Questionnaire-Patient (version)

EMA: Ecological Momentary Assessment

CO: Carbon Monoxide

\section{CBT: Cognitive Behavioural Therapy}

ITC: Intensive Treatment Comparison

All eight reviewed articles were published in English from the United States. Two of these articles reported pilot randomised controlled trials (RCTs), three reported qualitative studies, two reported pilot trials, one reported a full RCT and one reported a development study. The duration of studies ranged from three days to six months. The studies involved a total of only 131 participants. The main inclusion criteria entailed adults (18 years or older), smokers (smoke one or more cigarettes or using other types of tobacco products in a daily basis), with mental health issues, and using a smartphone. The studied intervention in the reviewed articles is smoking cessation app for smokers with mental health issues.

The primary outcome of six reviewed studies was smoking status of participants. Smoking status was measured in different ways, including self-reported smoking abstinence and biochemical verification of smoking abstinence with different follow-up. Four studies reported smoking abstinence with biochemical verification $[69,81,84,86]$. The duration of abstinence ranged from 7-day to 30-day. Secondary outcomes of reviewed studies included adherence, user experience, participant mental health status, acceptability and feasibility of the intervention.

Six studies concluded that smoking cessation apps support smokers with mental health conditions to quit smoking [69, 81, 83-86]. However, none of these studies had conclusive findings on the effectiveness of smoking cessation apps. User experience of smoking cessation apps varied across different studies $[68,69,82-85]$. The majority indicated smoking cessation apps achieved positive user experience, while one study stated that the smoking cessation app scored five points below industry standard (65.5 out of 100) on the user experience measuring scale [82]. The same study found that some features of smoking cessation app are redundant and rarely used [82]. Six studies measured participants' adherence to intervention activities. The majority of these studies reported a high compliance level of participants to intervention [68,69, 81, 82, 84], while one reported low compliance [85]. Only one study measured participants' mental health status [84]. This study indicated that the use of smoking cessation app lead to a significant decrease in depressive symptoms among app users [84].

Due to the diversity of study designs, participants, interventions, and outcome measures, and high risk of bias (Table 3), a meta-analysis of these studies was not appropriate [87].

Table 3: Risk of biases of the reviewed studies 


\begin{tabular}{|c|c|c|c|c|}
\hline Source & $\begin{array}{l}\text { Selection } \\
\text { bias }\end{array}$ & $\begin{array}{l}\text { Performance } \\
\text { bias }\end{array}$ & $\begin{array}{l}\text { Attrition } \\
\text { bias }\end{array}$ & Other bias \\
\hline \multirow{4}{*}{$\begin{array}{l}\text { Hertzberg et } \\
\text { al. } 2013[81]\end{array}$} & \multirow[t]{4}{*}{ Low } & \multirow[t]{4}{*}{ High } & \multirow[t]{4}{*}{ Low } & 1. Small sample size \\
\hline & & & & 2. Short follow-up period \\
\hline & & & & 3. Did not ask participants if they were receiving any PTSD treatment \\
\hline & & & & 4. Did not measure PTSD symptoms change \\
\hline \multirow{3}{*}{$\begin{array}{l}\text { Vilardaga et } \\
\text { al. } 2016[82]\end{array}$} & \multirow[t]{3}{*}{ High } & \multirow[t]{3}{*}{ NA } & \multirow[t]{3}{*}{ Low } & 1. Limited understanding of participants' psychiatric status (before and after intervention) \\
\hline & & & & 2. Limited time using the app \\
\hline & & & & $\begin{array}{l}\text { 3. Interviewer's characteristics (e.g. gender, investigator role) could have influenced study } \\
\text { procedures and interview results }\end{array}$ \\
\hline \multirow{3}{*}{$\begin{array}{l}\text { Hicks et al. } \\
2017 \text { [83] }\end{array}$} & \multirow[t]{3}{*}{ Low } & \multirow[t]{3}{*}{ High } & \multirow[t]{3}{*}{ Low } & 1. Small sample size \\
\hline & & & & $\begin{array}{l}\text { 2. Aspects of the current study underscore the potential for behavioural mobile health apps to } \\
\text { promote long-term abstinence in smokers with PTSD }\end{array}$ \\
\hline & & & & 3. Smoking status relied on self-reported data \\
\hline \multirow{2}{*}{$\begin{array}{l}\text { Minami et al. } \\
2018[69]\end{array}$} & \multirow[t]{2}{*}{ High } & \multirow[t]{2}{*}{ High } & \multirow[t]{2}{*}{ Low } & 1. Small sample size \\
\hline & & & & $\begin{array}{l}\text { 2. The generalisation of these findings to other populations may be limited as all participants } \\
\text { in this study were of low socioeconomic status }\end{array}$ \\
\hline \multirow{4}{*}{$\begin{array}{l}\text { Heffner et al. } \\
2019[84]\end{array}$} & \multirow[t]{4}{*}{ Low } & \multirow[t]{4}{*}{ High } & \multirow[t]{4}{*}{ Low } & 1. Small sample size \\
\hline & & & & 2. Study design: lack of a control group \\
\hline & & & & 3. Potential confounding effect: did not track non-study treatment use \\
\hline & & & & $\begin{array}{l}\text { 4. Selection bias: sample, on average, was of high socioeconomic status, had a low level of } \\
\text { nicotine dependence, and only included smokers with mild to moderate depression }\end{array}$ \\
\hline \multirow{5}{*}{$\begin{array}{l}\text { Herbst et al. } \\
2019[68]\end{array}$} & \multirow[t]{5}{*}{ High } & \multirow[t]{5}{*}{ NA } & \multirow[t]{5}{*}{ Low } & 1. Sample men exclusively from urban and suburban areas \\
\hline & & & & 2. The study did not examine the efficacy of the app \\
\hline & & & & 3. The study relied on self-report data of app usage \\
\hline & & & & 4. Potential of the therapeutic alliance that makes biased answers in interviews \\
\hline & & & & $\begin{array}{l}\text { 5. The study did not include specific questions about use of the app to cope with PTSD } \\
\text { symptoms }\end{array}$ \\
\hline $\begin{array}{l}\text { Wilson et al. } \\
2019[85]\end{array}$ & Low & NA & High & 1. Smoking status relied on self-reported data \\
\hline \multirow{3}{*}{$\begin{array}{l}\text { Alyssa et al. } \\
2020[86]\end{array}$} & \multirow[t]{3}{*}{ Low } & \multirow[t]{3}{*}{ High } & \multirow[t]{3}{*}{ Low } & 1. Small sample size \\
\hline & & & & 2. Unable to detect which treatment components determined the smoking cessation effect \\
\hline & & & & $\begin{array}{l}\text { 3. There was no post-treatment assessment to the control group, while the intervention group } \\
\text { had bio-verified data at post-treatment }\end{array}$ \\
\hline
\end{tabular}

Three studies had a high risk of selection bias - specific population groups (e.g. mental health smokers from high socioeconomic status) were invited to take part in these studies, leading to a lack of generalisability of the study results $[68,69,82]$. All reviewed trials had a high risk of performance bias because blinding was not performed by researchers or trial participants in any of these trials $[69,81,83,84,86]$. Majority of reviewed studies have small sample sizes and failed to detect a statistically significant smoking cessation outcome $[69,81,83,84,86]$. All studies had short to medium length of follow-up. Two studies had a six-month follow-up, while the other studies had less than three-month follow-up. The reviewed studies could not detect the long-term impacts of smoking cessation apps on smokers with mental health conditions. Two reviewed studies have no post-treatment assessment to the control group, which made it impossible to identify the size of the effect of the evaluated interventions $[84,86]$.

Step 2: Five smoking cessation apps for smokers with mental health conditions were identified from the reviewed studies. Details of these apps (both from literatures and app store search) are summarised in Table 4. All were built based on theories and clinical guidelines. Three had their development methods and processes discussed in the reviewed articles. Four focused on smokers with mental health conditions while one targeted all smokers. Two apps include functions for both smoking cessation and mental health management, but three had only functions for smoking cessation. Only two apps found in the systematic review were available in both Apple and Google App stores, two were only available in Apple App store, and one was not mentioned (no clarification of its availability in app stores). Two apps include the keyword "quit" in their name.

By searching these apps in app stores, three of them are unavailable in Apple or Google App store, one is available for free in Apple app store, while one is available free in both Apple and Google App stores. Only one app has its download rate available in the Google App store, the app named Stay Quit Coach has been downloaded over 10,000 times in the Google App store. The user rating scores are only available to two literature-based apps. The app named Actify! has 
its user rating score of 1.5 out of 5.0 in the Apple App store, while it was only rated by four users. Stay Quit Coach was rated as 3.5 out of 5.0 (No. of reviewers $=2$ ) in the Apple App store and rated as 4.0 out of 5.0 (No. of reviewers $=21$ ) in the Google App store.

Table 4: Details of apps identified from the reviewed studies

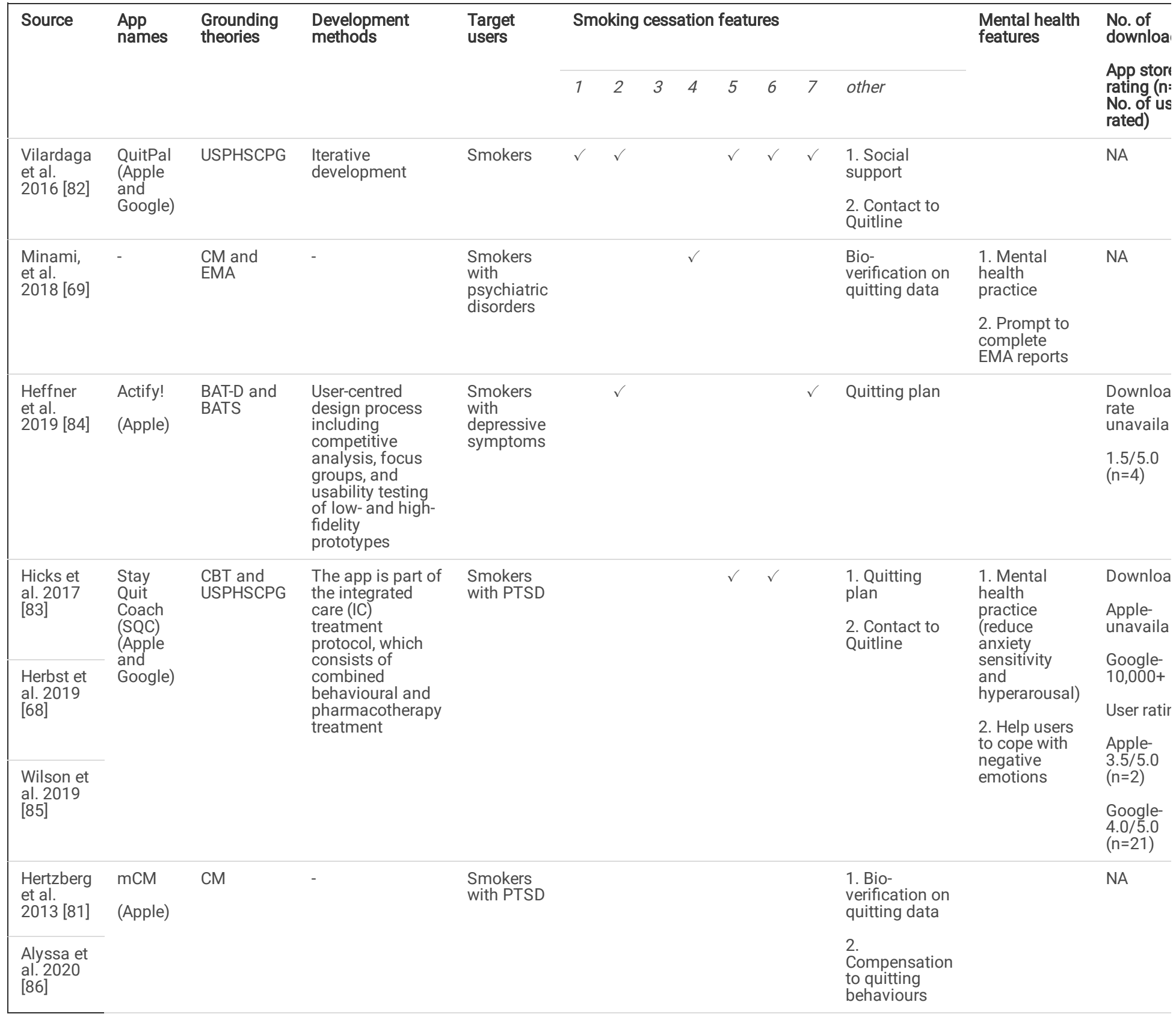




\begin{tabular}{|ll|}
\hline USPHCPG & US Public Health Service's Clinical Practice Guideline for Treating Tobacco Use and Dependence \\
\hline EMA & Ecological momentary assessment \\
\hline CM & Contingency management \\
\hline BAT-D & Behavioural Activation Treatment for Depression \\
\hline BATS & Behavioural Activation Treatment for Smoking \\
\hline CBT & Cognitive Behaviour Therapy \\
\hline PTSD & Posttraumatic Stress Disorder \\
\hline 1 & Calculator \\
\hline 2 & Calendar \\
\hline 3 & Gamification \\
\hline 4 & Hypnosis \\
\hline 5 & Information \\
\hline 6 & Lung Health Tester \\
\hline 7 & Rationing \\
\hline
\end{tabular}

Table 5: Details of apps found from the Apple and Google App Stores 


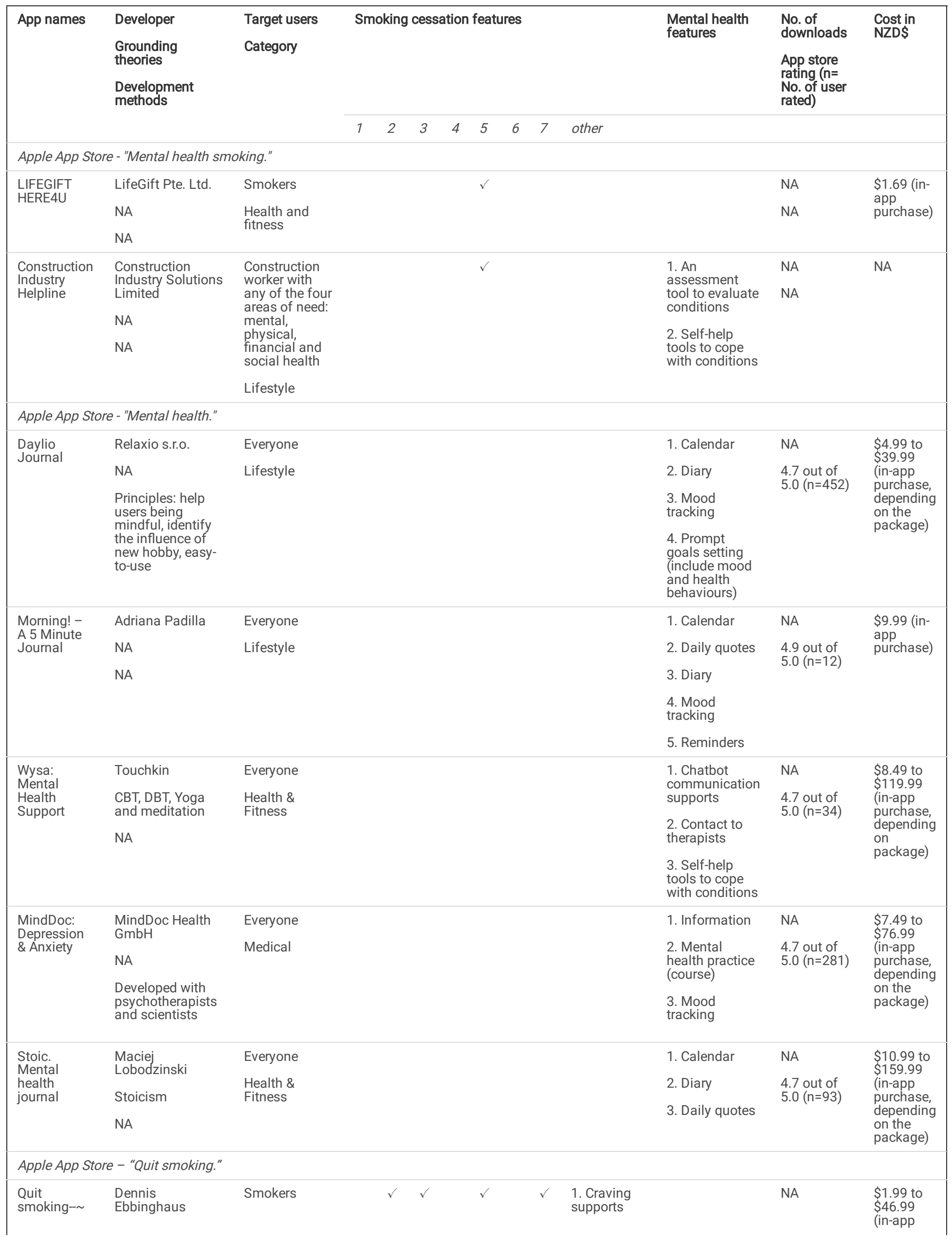

Page 10/21 


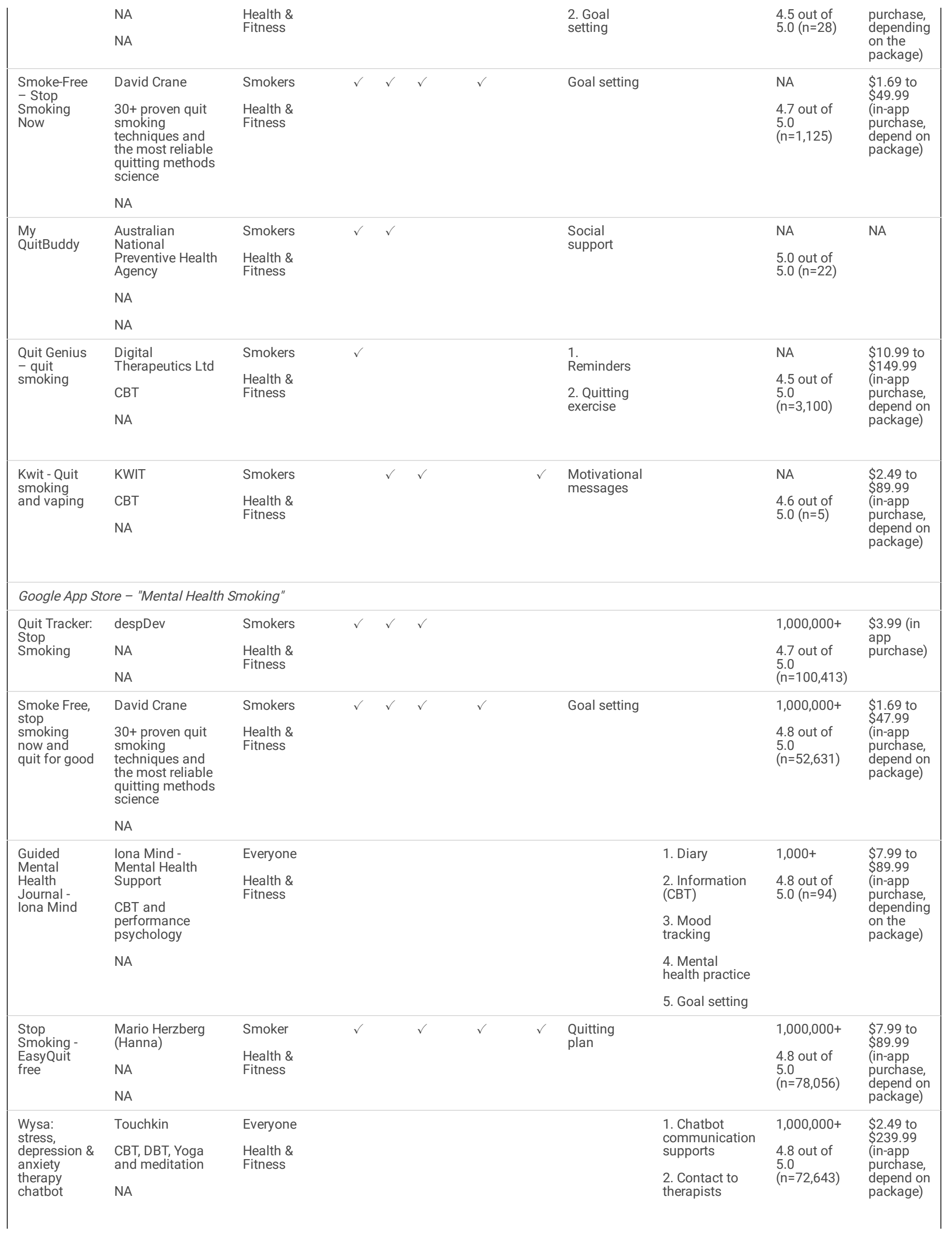

Page $11 / 21$ 
Google App Store - "Mental health."

Guided

Mental

Health

Journal -

Iona Mind

Wysa:

depression \&

anxiety

therapy

chatbot

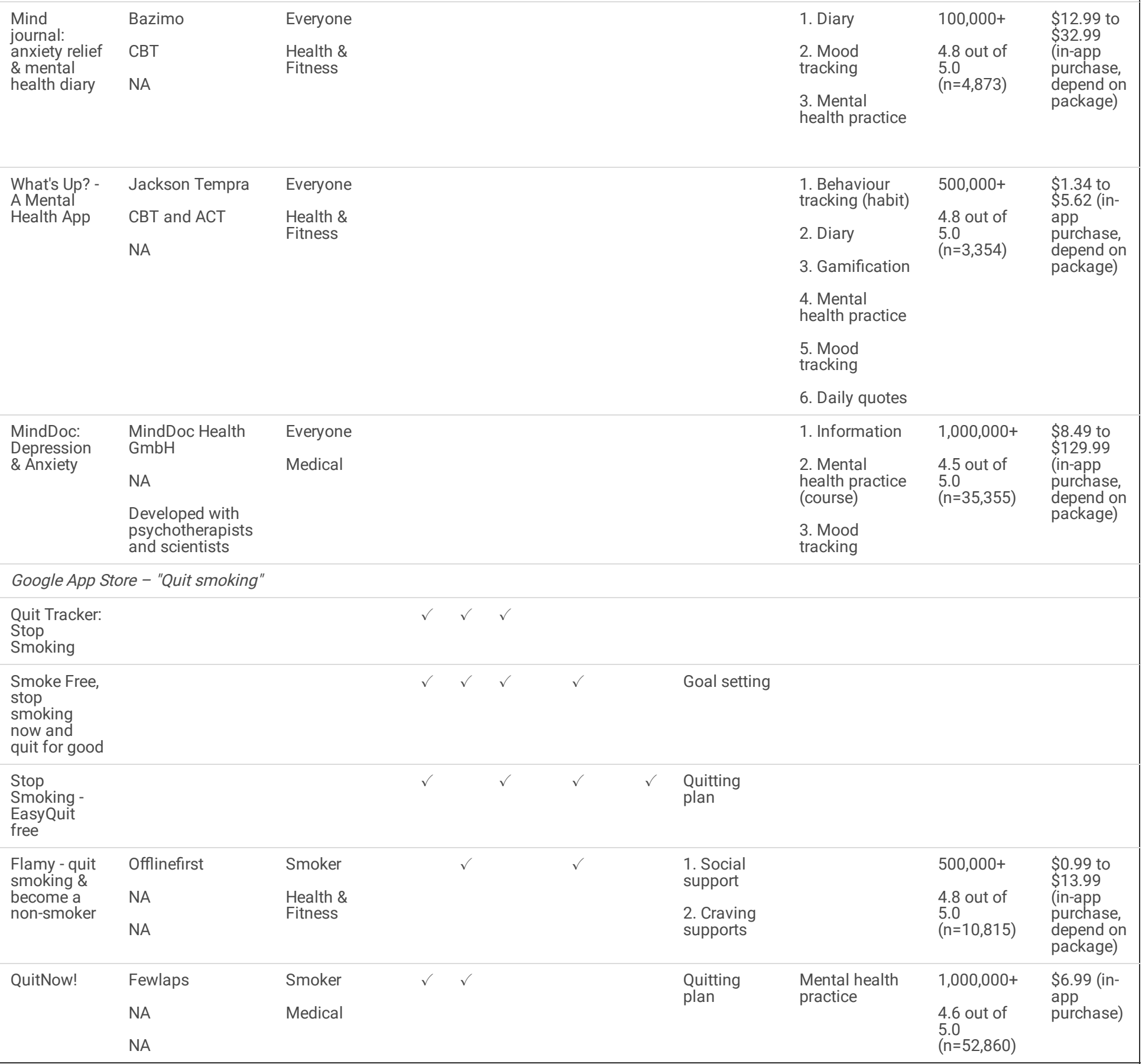




\begin{tabular}{|c|c|}
\hline CBT & Cognitive Behaviour Therapy \\
\hline DBT & Dialectical Behaviour Therapy \\
\hline 1 & Calculator \\
\hline 2 & Calendar \\
\hline 3 & Gamification \\
\hline 4 & Hypnosis \\
\hline 5 & Information \\
\hline 6 & Lung Health Tester \\
\hline 7 & Rationing \\
\hline
\end{tabular}

Phase 3: Identifying the top smoking cessation apps for smokers with mental health conditions, smoking cessation apps, and mental health apps available in app stores

Table 5 summarises the details of top listed apps identified from the app store search. The Apple App store search returned twelve apps and the Google App store returned ten apps (some apps exist more than once when searching by different keywords). Three apps (Wysa: Mental Health Support, MindDoc: Depression \& Anxiety, and Smoke Free - Stop Smoking Now) existed multiple times in both app stores and for different keywords. Some keywords like "mental health" ( $n=5)$, "smok*" ( $n=7)$, and "quit" $(n=8)$ are frequently existed in the names of the searched apps.

By entering "mental health smoking" into the Google App store, two of the top five returned apps are focusing on mental health conditions and three are focusing on smoking cessation. The most commonly seen smoking cessation functions are Calculator ( $n=3)$ and Gamification ( $n=3)$. By entering "mental health" into the same app store, the top five apps are all focusing on supporting mental health management. The most common functions of these apps are Mood tracking $(n=4)$, Mental health practice $(n=4)$, and Diary $(n=3)$. By entering "quit smoking" into the app store, four of the top five returned apps are focusing on supporting users to quit smoking, and one is focusing on both supporting smoking cessation and mental health management. The most common functions among these apps are Calendar $(n=4)$, Gamification $(n=3)$ and information $(n=3)$.

Ten out of twelve identified apps from the Apple App store require in-app purchase, which means some functions of the app are not available to users unless users pay for using. The price of these features ranged from $\$ 1.69$ to $\$ 159.99$ NZD (approx. $\$ 1.21$ to $\$ 114.81$ USD). All download rates were for apps in the Apple App store. Ten apps have their user rating scores available in the Apple App store. The average user rating score of these ten apps is 4.7 out of 5.0 (ranged from 4.5 to 5.0 out of 5.0). The average number of reviewers is 515 (ranged from 5 to 3100 reviewers).

All apps identified from the Google App store require in-app purchase. The price of these features ranged from NZD \$1.69 to \$239.99 (approx. \$1.21 to $\$ 172.22$ USD). Six of these apps were downloaded over 1,000,000 times, two were downloaded over 500,000 times, one was downloaded over 100,000 times and one was downloaded over 1,000 times. The average user rating score of these apps is 4.7 out of 5.0 (ranged from 4.5 to 4.8 out of 5.0 ). The average number of reviewers is 41,109 (ranged from 94 to 100,413 reviewers).

Phase 4: Identified which apps from the app stores were developed based on theories

All searched apps from the Apple App store $(n=12)$ were developed by individuals or commercial companies. Five out of twelve apps were developed by following theories to help their users. Two of these apps post their development methods in the app store page. All identified apps from the Google App store $(n=10)$ were developed by individuals or companies. Four of them use theory-based approaches to support their users. One shows its development method in the app store page.

Six apps from the Apple App store were developed to target on smokers, five were designed to support the general population who want to maintain good mental health, and one was developed to support construction workers. Eight of these apps are categorised as Health and Fitness apps, three as Lifestyle apps, and one as a Medical app. Five identified apps from the Google App store are targeting on smokers while the other five are targeting on general population. Eight of them are categorised as Health and Fitness apps, and two as Medical apps.

Most apps ( $\mathrm{n}=20$ out of 22 apps from both app stores) from app stores have either functions for supporting smoking cessation or managing mental health status. By entering "mental health smoking" into the Apple App store, only two apps were found. One has functions for both smoking cessation and mental health conditions. By entering "mental health" into the Apple App store, the top five returned apps are all focusing on mental health conditions. The most common functions among these apps are Calendar $(n=3)$, Dairy ( $n=3)$, and Mood tracking $(n=3)$. By entering "quit smoking" into the Apple App store, the top five returned apps are all focusing on supporting tobacco cessation. From these apps, the most commonly developed functions include Calendar ( $n=4)$, Calculator $(n=3)$, and Gamification $(n=3)$.

\section{Discussion}

This systematic review aimed to identify smoking cessation apps for smokers with mental health conditions. A search of studies from seven databases identified only eight studies, $75 \%$ of which provide some supportive evidence of positive impacts of smoking cessation apps on helping smokers with mental health conditions to quit smoking. Most of the reviewed articles were small pilot studies. It was impossible to conduct a meaningful meta-analysis with such 
heterogeneous measures [87]. Nevertheless, the narrative synthesis of evidence about mHealth app-based interventions for smoking cessation enables researchers to make several observations, as follows.

\section{Findings from reviewed studies}

Based on the reviewed studies, there are no standard methods to develop or evaluate smoking cessation apps for smokers with mental health conditions. In general, the sample sizes of current studies are small. Most reviewed studies were unable to detect statistically significant results.

Effectiveness of supporting smoking cessation and user experience are the two most commonly applied outcome measures of the reviewed studies. Most studies indicated that smoking cessation apps had some positive impacts on supporting smokers with mental health conditions to quit smoking. In contrast, two studies show that smoking cessation apps may weaken the effectiveness of another smoking cessation programme when used together [83, 86]. Other literature reviews [72] on smoking cessation apps and app content analysis [74, 75, 88-96], also draw the same conclusion: that the evidence for the effectiveness of smoking cessation apps on helping smokers to quit smoking is limited.

User satisfaction and perceived effectiveness were used to reflect the user experience of apps. Most reviewed studies found that participants perceived smoking cessation apps as a helpful tool to support smoking cessation. Two studies indicate that smoking cessation apps have average user satisfaction. For instance, the study done by Vilardaga et al. found that the app "QuitPal" was five points below the industry standard based on the rating done by the study participants on the SUS [82]. As mentioned by some smoking cessation app studies and reviews, limited evidence is available about the factors those increase a smoking cessation app's user experience. Some potential positive factors may include: providing multi-media information (e.g. audio, video) to users and built by following theories [21, 24, 29, 43, 50, 51, 92].

Although all studies targeted smokers with mental health conditions, only one study measured the mental health status of the participants. In Heffner's study, a significant decrease in PHQ score was found in participants who used the smoking cessation app to achieve smoking abstinence (mean change in PHQ-9 scores was $-4.5,95 \% \mathrm{Cl}-7.7$ to $-1.3 ; \boldsymbol{P}=.01$ ) [84]. However, the mechanism between quitting smoking and improving mental health status was not explained. The reason why mental health status was not included as an outcome measurement by most of the reviewed studies is not made clear, but what is clear is that that mental health status improvement should be an essential parameter to include in studies, given the strong correlation between tobacco use and mental health conditions [7-10].

\section{Findings from App Review}

Overall, 27 apps were discussed in this review (five reviewed literature-based apps, and twenty-two apps identified from the Apple and Google App stores). Key words like "mental health" $(n=5)$, "smok*" $(n=7)$, and "quit" $(n=8)$ are very common in apps from app stores than apps introduced in the reviewed studies. This may be the reason of why the literature-based apps were difficult to find in app stores (three out of five apps were unavailable). Instead of typing the names of the research-based apps, these apps were out of the top 50 searching results when typing terms like "mental health smoking", "mental health" and "quit smoking". It is very unlikely for smartphone users to download an app that requires too many scrolls or swipes [79, 80]. It will be worthwhile for researchers who are developing smoking cessation apps for smokers with mental health smokers to understand the logic of app stores for exhibiting apps in response to search. One technique is the use of hyphen between the app name and the aims of the app. For example, the apps' names like "What's Up? - A Mental Health App", "Stop Smoking - EasyQuit free", and "Flamy - quit smoking \& become a non-smoker" make them can be easily navigated when typing the correct key words.

All literature-based apps use approaches developed based on theories to support smoking cessation and mental health management. In comparison, less than half (41\%) of apps searched from app stores apply theory-based approaches. The finding of lack of theory-based approaches in health-related commercial apps is similar to other studies on health-related apps target on other conditions [97, 98]. The application of theory-based approaches to support smoking cessation and mental health management should be used as a marketing highlight to promote the literature-based apps or other research-based apps. Supportive evidence has been found from existing smoking cessation app analysis. Cheng et al. found that an smoking cessation app's theories and guideline adherence level is positively related to its rating in app stores [92]. Abroms et al. also found that a smoking cessation app's user experience rating is positively associated with its score on the application of theory and guideline-based approaches [73]. Although there are some exception scenarios, the application of theory-based approaches secure the safety, rigorousness and potentially the effectiveness of the apps.

Two literature-based apps have both smoking cessation and mental health management functions, while two apps searched from the app stores have functions from the both categories. However, the functions of app store searched apps are relatively easier in compared to literature-based apps. For instance, the app named "Construction Industry Helpline" has both smoking cessation and mental health-related functions, but the smoking cessation approach it uses is just providing smoking harms information to users. The situation is less common among research-based apps. For example, the app called "Stay Quit Coach" introduced by reviewed studies has multiple functions related to both smoking cessation and mental health management [68, 83, 85]. As introduced, smoking and mental health conditions are two strongly connected health conditions [7-10]. It is important to understand the mechanism between how these two factors affect one to the other before designing an appropriate smoking cessation app for smokers with mental health conditions.

The majority of apps searched from app stores only provide free trial versions for their users. The cost of these apps is varied. It shows the business potentials of smoking cessation and/or mental health management apps, but also reflect to the potential cost for maintaining these products. Although download rate is unavailable for apps from Apple App store, the identified apps from the Google App store provide some information about how popular these apps are. Based on the ten identified apps from the Google App store, six of them were downloaded over 1 million times. The massive difference in download rates reflects a vast difference between literature-based and commercial apps to reach their target users. Commercial apps also achieve higher user rating scores and are more likely to be rated by their users than literature-based apps. They provide some good examples and reference to research team about designing and 
developing an attractive and engaging app. Collaboration between research teams and commercial companies or applying app design standards [99, 100] from commercial companies can be a method to improve the attractiveness and engagement of research-based apps.

\section{Limitations}

There are a number of limitations in this systematic review. First, there was inconsistency of interventions and study settings, making a meta-analysis inappropriate [14]. Without a meta-analysis, no conclusive statements can be made about the impacts of smoking cessation apps on supporting smokers with mental health conditions. More standardised approaches to research design and evaluation would enable greater comparability between studies. Second, the quality of studies varied widely. Five trials had a small sample size ( $\mathrm{n}<50$ participants) and failed to detect statistically significant results. Most studies had a short follow-up (<3 months) and were unable to measure long-term impacts. Only one study measured changes in participants' mental health status. Studies with larger sample size, longer follow up and measures of a range of impacts are needed. A third limitation of this study is the limited number of apps included in our analysis ( $\mathrm{n}=27$, five based on reviewed literature and 22 from app stores). Commercial apps were the top five apps in the two major app stores but there are hundreds of apps available in both app stores that were not reviewed.

\section{Conclusion}

This study used a systematic method to identify and review current studies of smoking cessation apps for smokers with mental health conditions. There is currently insufficient evidence that smoking cessation apps are effective at supporting people with mental health conditions to quit smoking. There is a lack of data on the size of the effect and the impact of these apps on users' mental health conditions. Research-based apps were usually perceived as effective by their users, and usually have theory-based approaches to support their users. However, compared to commercial-based apps, research-based apps have a lack of attractiveness and engagement. The marketing strategies for research-based apps need to be improved. Using a better naming strategy and following industrial standards to design apps would be a good starting point. The logical next step for future study would thus be developing a smoking cessation app for smokers with mental health conditions based on scientific evidence (including theories and relevant clinical guidelines), as well as learning from popular commercial-based apps. Future randomised controlled trials of such apps should aim for larger sample sizes, longer follow up periods and use more comprehensive outcome measures.

\section{Abbreviations}

COPD: Chronic Obstructive Pulmonary Disease

PRISMA: Preferred Reporting Items for Systematic Reviews and Meta-Analyses

NTCC: National Tobacco Cessation Collaboration

SUS: System Usability Scale

PPA: Point Prevalence Abstinence

PHQ: Patient Health Questionnaire

PTSD: Post-Traumatic Stress Disorder

PMPIQ-P: Perceptions of Mobile Phone Interventions Questionnaire-Patient (version)

EMA: Ecological Momentary Assessment

CO: Carbon Monoxide

CBT: Cognitive Behavioural Therapy

ITC: Intensive Treatment Comparison

RCTs: Randomised Controlled Trials

USPHCPG: US Public Health Service's Clinical Practice Guideline for Treating Tobacco Use and Dependence

CM: Contingency management

BAT-D: Behavioural Activation Treatment for Depression

BATS: Behavioural Activation Treatment for Smoking

SQC: Stay Quit Coach

\section{Declarations}

Ethics approval and consent to participate 
Not applicable

Consent for publication

Not applicable

Availability of data and materials

Data used to draw the findings of literature review of the current study are available from the reviewed articles, data used to draw the findings of app review of the current study are available from the app stores and the corresponding author on reasonable request.

\section{Competing interests}

The authors declare that they have no competing interests.

Funding

The current study is funded by the Ember Korowai Takitini Research Grant. The funding body did not take part in the design of the study, or the collection, analysis, and interpretation of data, or in writing the manuscript.

Authors' contribution

Jche ran the literature and app search, extracted and analysed the data, and wrote the manuscript. CB, JC and SM reviewed the data analysis and co-wrote the manuscript. All authors read and approved the final manuscript.

Acknowledgements

The Ember Korowai Takitini is the funder of the current study. Ember Korowai Takitini provides funding for all study related operation of the current study.

\section{References}

1. World Health Organization: WHO report on the global tobacco epidemic 2019: offer help to quit tobacco use. In.: WHO; 2019.

2. Shiffman S, Brockwell SE, Pillitteri JL, Gitchell JG: Use of Smoking-Cessation Treatments in the United States. American Journal of Preventive Medicine 2008, 34(2):102-111.

3. Zhang M, Wang LM, Li YC, Li XY, Jiang Y, Hu N, Xiao L, Li Q, Yang Y, Yang GH: [Cross-sectional survey on smoking and smoking cessation behaviors among Chinese adults in 2010]. Zhonghua Yu Fang Yi Xue Za Zhi 2012, 46(5):404-408.

4. Khan N, Anderson JR, Du J, Tinker D, Bachyrycz AM, Namdar R: Smoking cessation and its predictors: results from a community-based pharmacy tobacco cessation program in New Mexico. Ann Pharmacother 2012, 46(9):1198-1204.

5. Chen J, Ho E, Jiang Y, Whittaker R, Yang T, Bullen C: Mobile Social Network-Based Smoking Cessation Intervention for Chinese Male Smokers: Pilot Randomized Controlled Trial. JMIR Mhealth Uhealth 2020, 8(10):e17522.

6. mTobaccoCessation: Mobilizing technology for a smoke-free world [http://www.who.int/tobacco/quitting/mtobaccocessation/en/]

7. Cafarella PA, Effing TW, Usmani ZA, Frith PA: Treatments for anxiety and depression in patients with chronic obstructive pulmonary disease: a literature review. Respirology 2012, 17(4):627-638.

8. Global Initiative for Chronic Obstructive Lung Disease (GOLD). 2014. Global Strategy for the Diagnosis, Management and Prevention of COPD. http://www.goldcopd.org/. Assessed on 27/01/2020.

9. Lisa Cantor, Jacobson R. 2003. COPD: How to manage comorbid depression and anxiety. https://www.mdedge.com/psychiatry/article/59764/depression/copd-how-manage-comorbid-depression-and-anxiety. Assessed on 27/01/2020.

10. National Health Service. 2018. Stopping smoking is good for your mental health https://www.nhs.uk/live-well/quit-smoking/stopping-smoking-mentalhealth-benefits/. Assessed on 27/01/2020.

11. Yohannes AM, Alexopoulos GS: Depression and anxiety in patients with COPD. European Respiratory Review 2014, 23(133):345.

12. Tselebis A, Pachi A, llias I, Kosmas E, Bratis D, Moussas G, Tzanakis N: Strategies to improve anxiety and depression in patients with CoPD: a mental health perspective. Neuropsychiatr Dis Treat 2016, 12:297-328.

13. National Health Service. 2018. Stopping smoking is good for your mental health. New Zealand. https://www.nhs.uk/live-well/quit-smoking/stoppingsmoking-mental-health-benefits/. Assessed on 2020/02/25.

14. Whittaker R, McRobbie H, Bullen C, Rodgers A, Gu Y, Dobson R: Mobile phone text messaging and app-based interventions for smoking cessation. Cochrane Database Syst Rev 2019(10).

15. Keoleian V, Polcin D, Galloway GP: Text messaging for addiction: a review. J Psychoactive Drugs 2015, 47(2):158-176.

16. Hall AK, Cole-Lewis H, Bernhardt JM: Mobile text messaging for health: a systematic review of reviews. Annu Rev Public Health 2015, 36:393-415.

17. Jamison J, Naughton F, Gilbert H, Sutton S: Delivering Smoking Cessation Support by Mobile Phone Text Message: What Information do Smokers Want? A Focus Group Study. Journal of Applied Biobehavioral Research 2013, 18(1):1-23. 
18. Schwartz RP, Gryczynski J, Mitchell SG, Gonzales A, Moseley A, Peterson TR, Ondersma SJ, O'Grady KE: Computerized versus in-person brief intervention for drug misuse: a randomized clinical trial. Addiction 2014, 109(7):1091-1098.

19. BinDhim NF, McGeechan K, Trevena L: Assessing the effect of an interactive decision-aid smartphone smoking cessation application (app) on quit rates: a double-blind automated randomised control trial protocol. BMJ open 2014, 4(7):e005371.

20. Bricker JB, Mull KE, Kientz JA, Vilardaga R, Mercer LD, Akioka KJ, Heffner JL: Randomized, controlled pilot trial of a smartphone app for smoking cessation using acceptance and commitment therapy. Drug Alcohol Depend 2014, 143:87-94.

21. Buller DB, Borland R, Bettinghaus EP, Shane JH, Zimmerman DE: Randomized trial of a smartphone mobile application compared to text messaging to support smoking cessation. Telemedicine journal and e-health : the official journal of the American Telemedicine Association 2014, 20(3):206-214.

22. Ploderer B, Smith W, Pearce J, Borland R: A mobile app offering distractions and tips to cope with cigarette craving: a qualitative study. JMIR mhealth uhealth 2014, 2(2):e23.

23. Ubhi HK, Michie S, Kotz D, Wong WC, West R: A mobile app to aid smoking cessation: preliminary evaluation of SmokeFree28. Journal of medical Internet research 2015, 17(1):e17.

24. McClure JB, Anderson ML, Bradley K, An LC, Catz SL: Evaluating an Adaptive and Interactive mHealth Smoking Cessation and Medication Adherence Program: A Randomized Pilot Feasibility Study. JMIR mhealth uhealth 2016, 4(3).

25. Naughton F, Hopewell S, Lathia N, Schalbroeck R, Brown C, Mascolo C, McEwen A, Sutton S: A Context-Sensing Mobile Phone App (Q Sense) for Smoking Cessation: A Mixed-Methods Study. JMIR mhealth uhealth 2016, 4(3):e106

26. Vilardaga R, Rizo J, Kientz JA, McDonell MG, Ries RK, Sobel K: User experience evaluation of a smoking cessation app in people With serious mental illness. Nicotine Tob Res 2016, 18(5):1032-1038.

27. Bricker JB, Copeland W, Mull KE, Zeng EY, Watson NL, Akioka KJ, Heffner JL: Single-arm trial of the second version of an acceptance \& commitment therapy smartphone application for smoking cessation. Drug Alcohol Depend 2017, 170:37-42.

28. Gordon JS, Armin JS, Cunningham JK, Muramoto ML, Christiansen SM, Jacobs TA: Lessons learned in the development and evaluation of RxCoach, an mHealth app to increase tobacco cessation medication adherence. Patient education and counseling 2017, 100(4):720-727.

29. Hassandra M, Lintunen T, Hagger MS, Heikkinen R, Vanhala M, Kettunen T: An mHealth App for Supporting Quitters to Manage Cigarette Cravings With Short Bouts of Physical Activity: A Randomized Pilot Feasibility and Acceptability Study. JMIR mhealth uhealth 2017, 5(5):e74.

30. Hicks TA, Thomas SPMS, Wilson SMP, Calhoun PSP, Kuhn ERP, Beckham JCP: A Preliminary Investigation of a Relapse Prevention Mobile Application to Maintain Smoking Abstinence Among Individuals With Posttraumatic Stress Disorder. J Dual Diagn 2017, 13(1):15-20.

31. lacoviello BM, Steinerman JR, Klein DB, Silver TL, Berger AG, Luo SX, Schork NJ: Clickotine, A Personalized Smartphone App for Smoking Cessation: Initial Evaluation. JMIR mhealth uhealth 2017, 5(4):e56.

32. Pechmann C, Delucchi K, Lakon CM, Prochaska JJ: Randomised controlled trial evaluation of Tweet2Quit: a social network quit-smoking intervention. Tob Control 2017, 26(2):188-194.

33. Regmi K, Kossim N, Ahmod NH, Tuoh NA: Assessment of content, quality and compliance of the STaR mobile application for smoking cessation. Tob Prev Cessation 2017, 3

34. Singh S, Starkey NJ, Sargisson RJ: Using SmartQuit(R), an Acceptance and Commitment Therapy Smartphone application, to reduce smoking intake. Digit Health 2017, 3:2055207617729535.

35. Wu J, Tombor I, Shahab L, West R: Usability testing of a smoking cessation smartphone application ('SmokeFree Baby'): A think-aloud study with pregnant smokers. Digit Health 2017, 3:2055207617704273.

36. BinDhim NF, McGeechan K, Trevena L: Smartphone Smoking Cessation Application (SSC App) trial: a multicountry double-blind automated randomised controlled trial of a smoking cessation decision-aid 'app'. BMJ open 2018, 8(1):e017105.

37. Crane D, Ubhi HK, Brown J, West R: Relative effectiveness of a full versus reduced version of the 'Smoke Free' mobile application for smoking cessation: an exploratory randomised controlled trial. F1000Res 2018, 7:1524.

38. Dar R: Effect of Real-Time Monitoring and Notification of Smoking Episodes on Smoking Reduction: A Pilot Study of a Novel Smoking Cessation App. Nicotine Tob Res 2018, 20(12):1515-1518.

39. Garrison KA, Pal P, O'Malley SS, Pittman BP, Gueorguieva R, Rojiani R, Scheinost D, Dallery J, Brewer JA: Craving to Quit: A Randomized Controlled Trial of Smartphone app-based Mindfulness Training for Smoking Cessation. Nicotine Tob Res 2018.

40. McClure EA, Tomko RL, Carpenter MJ, Treiber FA, Gray KM: Acceptability and compliance with a remote monitoring system to track smoking and abstinence among young smokers. Am J Drug Alcohol Abuse 2018, 44(5):561-570.

41. Patrick H, Fujii CA, Glaser DB, Utley DS, Marler JD: A Comprehensive Digital Program for Smoking Cessation: Assessing Feasibility in a Single-Group Cohort Study. JMIR mhealth uhealth 2018, 6(12):e11708.

42. Schick RS, Kelsey TW, Marston J, Samson K, Humphris GW: MapMySmoke: feasibility of a new quit cigarette smoking mobile phone application using integrated geo-positioning technology, and motivational messaging within a primary care setting. Pilot Feasibility Stud 2018, 4:19.

43. Shuter J, Kim RS, An LC, Abroms LC: Feasibility of a smartphone-based tobacco treatment for HIV-infected smokers. Nicotine Tob Res 2018.

44. Tan NC, Mohd Mohtar ZB, Koh EYL, Sankari U, Tay DHC, Yu S, Tan WBW: An exhaled carbon monoxide self-monitoring device linked to social media to support smoking cessation: A proof of concept pilot study. Proc Singapore Healthc 2018, 27(3):187-192.

45. Tudor-Sfetea C, Rabee R, Najim M, Amin N, Chadha M, Jain M, Karia K, Kothari V, Patel T, Suseeharan M et al: Evaluation of Two Mobile Health Apps in the Context of Smoking Cessation: Qualitative Study of Cognitive Behavioral Therapy (CBT) Versus Non-CBT-Based Digital Solutions. JMIR mhealth uhealth 2018, 6(4).

Page $17 / 21$ 
46. Heffner JL, Watson NL, Serfozo E, Mull KE, MacPherson L, Gasser M, Bricker JB: A Behavioral Activation Mobile Health App for Smokers With Depression: Development and Pilot Evaluation in a Single-Arm Trial. JMIR Form Res 2019, 3(4):e13728.

47. Herbec A, Brown J, Shahab L, West R, Raupach T: Pragmatic randomised trial of a smartphone app (NRT2Quit) to improve effectiveness of nicotine replacement therapy in a quit attempt by improving medication adherence: results of a prematurely terminated study. Trials 2019, 20(1):547.

48. Herbst E, McCaslin SE, Daryani SH, Laird KT, Hopkins LB, Pennington D, Kuhn E: A Qualitative Examination of Stay Quit Coach, a Mobile Application for Veteran Smokers with Posttraumatic Stress Disorder. Nicotine Tob Res 2019.

49. Hoeppner BB, Hoeppner SS, Carlon HA, Perez GK, Helmuth E, Kahler CW, Kelly JF: Leveraging Positive Psychology to Support Smoking Cessation in Nondaily Smokers Using a Smartphone App: Feasibility and Acceptability Study. JMIR mhealth uhealth 2019, 7(7):e13436.

50. Krebs P, Burkhalter J, Fiske J, Snow H, Schofield E, locolano M, Borderud S, Ostroff JS: The QuitIT Coping Skills Game for Promoting Tobacco Cessation Among Smokers Diagnosed With Cancer. Pilot Randomized Controlled Trial. JMIR mhealth uhealth 2019, 7(1):e10071.

51. Krishnan N, Elf JL, Chon S, Golub JE: COach2Quit: A Pilot Randomized Controlled Trial of a Personal Carbon Monoxide Monitor for Smoking Cessation. Nicotine Tob Res 2019, 21(11):1573-1577.

52. Luna-Perejon F, Malwade S, Styliadis C, Civit J, Cascado-Caballero D, Konstantinidis E, Abdul SS, Bamidis PD, Civit A, Li YC: Evaluation of user satisfaction and usability of a mobile app for smoking cessation. Comput Meth Prog Bio 2019, 182.

53. Marler JD, Fujii CA, Utley DS, Tesfamariam LJ, Galanko JA, Patrick H: Initial Assessment of a Comprehensive Digital Smoking Cessation Program That Incorporates a Mobile App, Breath Sensor, and Coaching: Cohort Study. JMIR mhealth uhealth 2019, 7(2):e12609.

54. Masaki K, Tateno H, Kameyama N, Morino E, Watanabe R, Sekine K, Ono T, Satake K, Suzuki S, Nomura A et al: Impact of a Novel Smartphone App (CureApp Smoking Cessation) on Nicotine Dependence: Prospective Single-Arm Interventional Pilot Study. JMIR mhealth uhealth 2019, 7(2):e12694.

55. O'Connor M, Whelan R, Bricker J, McHugh L: Randomized Controlled Trial of a Smartphone Application as an Adjunct to Acceptance and Commitment Therapy for Smoking Cessation. Behav Ther 2019.

56. Pbert L, Druker S, Crawford S, Frisard C, Trivedi M, Osganian SK, Brewer J: Feasibility of a Smartphone App with Mindfulness Training for Adolescent Smoking Cessation: Craving to Quit (C2Q)-Teen. Mindfulness 2019.

57. Peiris D, Wright L, News M, Rogers K, Redfern J, Chow C, Thomas D: A Smartphone App to Assist Smoking Cessation Among Aboriginal Australians: Findings From a Pilot Randomized Controlled Trial. JMIR mhealth uhealth 2019, 7(4):e12745.

58. Schlam TR, Baker TB: Playing Around with Quitting Smoking: A Randomized Pilot Trial of Mobile Games as a Craving Response Strategy. Games Health $J 2019$.

59. Sridharan V, Shoda Y, Heffner J, Bricker J: A Pilot Randomized Controlled Trial of a Web-Based Growth Mindset Intervention to Enhance the Effectiveness of a Smartphone App for Smoking Cessation. JMIR mhealth uhealth 2019, 7(7):e14602.

60. Tombor I, Beard E, Brown J, Shahab L, Michie S, West R: Randomized factorial experiment of components of the SmokeFree Baby smartphone application to aid smoking cessation in pregnancy. Transl Behav Med 2019, 9(4):583-593.

61. Bricker JB, Watson NL, Heffner JL, Sullivan B, Mull K, Kwon D, Westmaas JL, Ostroff J: A Smartphone App Designed to Help Cancer Patients Stop Smoking: Results From a Pilot Randomized Trial on Feasibility, Acceptability, and Effectiveness. JMIR Form Res 2020, 4(1):e16652.

62. Bricker JB, Watson NL, Mull KE, Sullivan BM, Heffner JL: Efficacy of Smartphone Applications for Smoking Cessation: A Randomized Clinical Trial. JAMA Intern Med 2020, 180(11):1-9.

63. Goldenhersch E, Thrul J, Ungaretti J, Rosencovich N, Waitman C, Ceberio MR: Virtual reality smartphone-based intervention for smoking cessation: Pilot randomized controlled trial on initial clinical efficacy and adherence. Journal of medical Internet research 2020, 22(7):e17571.

64. Hebert ET, Ra CK, Alexander AC, Helt A, Moisiuc R, Kendzor DE, Vidrine DJ, Funk-Lawler RK, Businelle MS: A mobile just-in-time adaptive intervention for smoking cessation: Pilot randomized controlled trial. Journal of medical Internet research 2020, 22(3):e16907.

65. Masaki K, Tateno H, Nomura A, Muto T, Suzuki S, Satake K, Hida E, Fukunaga K: A randomized controlled trial of a smoking cessation smartphone application with a carbon monoxide checker. npj Digital Medicine 2020, 3(1):35.

66. Pallejà-Millán M, Rey-Reñones C, Barrera Uriarte ML, Granado-Font E, Basora J, Flores-Mateo G, Duch J: Evaluation of the Tobbstop Mobile App for Smoking Cessation: Cluster Randomized Controlled Clinical Trial. JMIR Mhealth Uhealth 2020, 8(6):e15951.

67. Webb J, Peerbux S, Smittenaar P, Siddiqui S, Sherwani Y, Ahmed M, MacRae H, Puri H, Bhalla S, Majeed A: Preliminary Outcomes of a Digital Therapeutic Intervention for Smoking Cessation in Adult Smokers: Randomized Controlled Trial. JMIR Ment Health 2020, 7(10):e22833.

68. Herbst E, McCaslin SE, Hassanbeigi Daryani S, Laird KT, Hopkins LB, Pennington D, Kuhn E: A Qualitative Examination of Stay Quit Coach, A Mobile Application for Veteran Smokers With Posttraumatic Stress Disorder. Nicotine Tob Res 2020, 22(4):560-569.

69. Minami H, Brinkman HR, Nahvi S, Arnsten JH, Rivera-Mindt M, Wetter DW, Bloom EL, Price LH, Vieira C, Donnelly R et al: Rationale, design and pilot feasibility results of a smartphone-assisted, mindfulness-based intervention for smokers with mood disorders: Project mSMART MIND. Contemp Clin Trials 2018, 66:36-44.

70. BinDhim NF, McGeechan K, Trevena L: Who Uses Smoking Cessation Apps? A Feasibility Study Across Three Countries via Smartphones. JMIR Mhealth Uhealth 2014, 2(1):e4.

71. Chu K-H, Matheny SJ, Escobar-Viera CG, Wessel C, Notier AE, Davis EM: Smartphone health apps for tobacco Cessation: A systematic review. Addictive Behaviors 2021, 112:106616.

72. Haskins BL, Lesperance D, Gibbons P, Boudreaux ED: A systematic review of smartphone applications for smoking cessation. Trans/ Behav Med 2017, 7(2):292-299. 
73. Abroms LC, Lee Westmaas J, Bontemps-Jones J, Ramani R, Mellerson J: A content analysis of popular smartphone apps for smoking cessation. Am J Prev Med 2013, 45(6):732-736.

74. Choi J, Noh GY, Park DJ: Smoking cessation apps for smartphones: content analysis with the self-determination theory. Journal of medical Internet research 2014, 16(2):e44.

75. Watson AM, Alber JM, Barnett TE, Mercado R, Bernhardt JM: Content Analysis of Anti-Tobacco Videogames: Characteristics, Content, and Qualities. Games Health J 2016, 5(3):216-223.

76. Moher D, Liberati A, Tetzlaff J, Altman DG: Preferred reporting items for systematic reviews and meta-analyses: the PRISMA statement. BMJ 2009, 339:b2535.

77. Whittaker R, McRobbie H, Bullen C, Rodgers A, Gu Y, Dobson R: Mobile phone text messaging and app-based interventions for smoking cessation. Cochrane Database of Systematic Reviews 2019(10).

78. National Tobacco Cessation Collaborative. 2008. Quit Smoking Apps on the iPhone. http://www.tobacco-cessation.org/news/news_dec08.htm\#spotlight. Assessed on 2021/04.

79. Jakob N. 2001. Search: Visible and Simple. Neilsen Norman Group. https://www.nngroup.com/articles/search-visible-and-simple/. Assessed on 2021/04.

80. Jakob N. 2010. Scrolling and Attention. Neilsen Norman Group. https://www.nngroup.com/articles/scrolling-and-attention/. Assessed on $2021 / 04$.

81. Hertzberg JS, Carpenter VL, Kirby AC, Calhoun PS, Moore SD, Dennis MF, Dennis PA, Dedert EA, Beckham JC: Mobile contingency management as an adjunctive smoking cessation treatment for smokers with posttraumatic stress disorder. Nicotine Tob Res 2013, 15(11):1934-1938.

82. Vilardaga R, Rizo J, Kientz JA, McDonell MG, Ries RK, Sobel K: User experience evaluation of a smoking cessation app in people With serious mental illness. Nicotine and Tobacco Research 2016, 18(5):1032-1038.

83. Hicks TAB, Thomas SP, Wilson SM, Calhoun PS, Kuhn ER, Beckham JC: A Preliminary Investigation of a Relapse Prevention Mobile Application to Maintain Smoking Abstinence Among Individuals With Posttraumatic Stress Disorder. J Dual Diagn 2017, 13(1):15-20.

84. Heffner JL, Watson NL, Serfozo E, Mull KE, MacPherson L, Gasser M, Bricker JB: A behavioral activation mobile health app for smokers with depression: Development and pilot evaluation in a single-arm trial. Journal of Medical Internet Research 2019, 21(11).

85. Wilson SM, Thompson AC, Currence ED, Thomas SP, Dedert EA, Kirby AC, Elbogen EB, Moore SD, Calhoun PS, Beckham JC: Patient-Informed Treatment Development of Behavioral Smoking Cessation for People With Schizophrenia. Behav Ther 2019, 50(2):395-409.

86. Medenblik AM, Mann AM, Beaver TA, Dedert EA, Wilson SM, Calhoun PS, Beckham JC: Treatment Outcomes of a Multi-Component Mobile Health Smoking Cessation Pilot Intervention for People with Schizophrenia. J Dual Diagn 2020:1-9.

87. Deeks JJ, Higgins JP, Altman DG, Group obotCSM: Analysing data and undertaking meta-analyses. In: Cochrane Handbook for Systematic Reviews of Interventions. edn.; 2019: 241-284.

88. Bennett ME, Toffey K, Dickerson F, Himelhoch S, Katsafanas E, Savage CLG: A Review of Android Apps for Smoking Cessation. J Smok Cessat 2015, 10(2):106-115.

89. Heffner JL, Vilardaga R, Mercer LD, Kientz JA, Bricker JB: Feature-level analysis of a novel smartphone application for smoking cessation. Am J Drug Alcohol Abuse 2015, 41(1):68-73.

90. Ubhi HK, Kotz D, Michie S, van Schayck OC, Sheard D, Selladurai A, West R: Comparative analysis of smoking cessation smartphone applications available in 2012 versus 2014. Addict Behav 2016, 58:175-181.

91. Ubhi HK, Michie S, Kotz D, van Schayck OC, Selladurai A, West R: Characterising smoking cessation smartphone applications in terms of behaviour change techniques, engagement and ease-of-use features. Trans/ Behav Med 2016, 6(3):410-417.

92. Cheng F, Xu J, Su C, Fu X, Bricker J: Content Analysis of Smartphone Apps for Smoking Cessation in China: Empirical Study. JMIR mhealth uhealth 2017, 5(7):e93.

93. Ferron JC, Brunette MF, Geiger P, Marsch LA, Adachi-Mejia AM, Bartels SJ: Mobile Phone Apps for Smoking Cessation: Quality and Usability Among Smokers With Psychosis. JMIR Hum Factors 2017, 4(1):e7.

94. Thornton L, Quinn C, Birrell L, Guillaumier A, Shaw B, Forbes E, Deady M, Frances KL: Free smoking cessation mobile apps available in Australia: a quality review and content analysis. AUST NZ J Publ Hea/ 2017, 41(6):625-630.

95. Regmi D, Tobutt C, Shaban S: Quality and Use of Free Smoking Cessation Apps for Smartphones. Int J Technol Assess Health Care 2018, 34(5):476-480.

96. Robinson CD, Seaman EL, Grenen E, Montgomery L, Yockey RA, Coa K, Prutzman Y, Augustson E: A content analysis of smartphone apps for adolescent smoking cessation. Trans/ Behav Med 2018.

97. Conroy DE, Yang CH, Maher JP: Behavior change techniques in top-ranked mobile apps for physical activity. Am J Prev Med 2014, 46(6):649-652.

98. Cowan LT, Van Wagenen SA, Brown BA, Hedin RJ, Seino-Stephan Y, Hall PC, West JH: Apps of steel: are exercise apps providing consumers with realistic expectations?: a content analysis of exercise apps for presence of behavior change theory. Health Educ Behav 2013, 40(2):133-139.

99. Tencent. 2019. WeChat Mini-programme Design Guideline. https://developers.weixin.qq.com/miniprogram/design/. Assessed on $2019 / 06$.

100. Google Inc. 2021. Google Material User Interface Design Guideline. https://material.io/design. Assessed on 2021/03/06.

\section{Appendices}

Appendix 1. Search Strategies on Databases

EMBASE

Page 19/21 
(Smoking or smoking cessation or quit smoking or stop smoking or cigarette or cigarette cessation or tobacco or tobacco cessation).mp. [mp=ti, ab, tx, ct] AND (Smartphone or mobile phone or phone or iPhone or iOS or Android or smartphone or cell phone).mp. [mp=ti, ab, tx, ct] AND (App* or application or mobile app* or mobile software or mobile program* or smartphone app* or smartphone software or smartphone program*).mp. [mp=ti, ab, tx, ct] AND (Anxiety or depression or stress or emotion* or mental or mental health or mental health wellbeing or mental disorder* or mental illness* or psychiatric disorder*).mp. [mp=ti, ab, tx, ct]

\section{MEDLINE}

(Smoking or smoking cessation or quit smoking or stop smoking or cigarette or cigarette cessation or tobacco or tobacco cessation).mp. [mp=ti, ab, tx, ct] AND (Smartphone or mobile phone or phone or iPhone or iOS or Android or smart phone or cell phone).mp. [mp=ti, ab, tx, ct] AND (App* or application or mobile app* or mobile software or mobile program* or smartphone app* or smartphone software or smartphone program*).mp. [mp=ti, ab, tx, ct] AND (Anxiety or depression or stress or emotion* or mental or mental health or mental health wellbeing or mental disorder* or mental illness* or psychiatric disorder*).mp. $[\mathrm{mp}=\mathrm{ti}, \mathrm{ab}, \mathrm{tx}, \mathrm{ct}]$

\section{APA Psyclnfo}

(Smoking or smoking cessation or quit smoking or stop smoking or cigarette or cigarette cessation or tobacco or tobacco cessation).mp. [mp=ti, ab, tx, ct] AND (Smartphone or mobile phone or phone or iPhone or iOS or Android or smart phone or cell phone).mp. [mp=ti, ab, tx, ct] AND (App* or application or mobile app* or mobile software or mobile program* or smartphone app* or smartphone software or smartphone program).mp. [mp=ti, ab, tx, ct] AND (Anxiety or depression or stress or emotion* or mental or mental health or mental health wellbeing or mental disorder* or mental illness* or psychiatric disorder*).mp. $[\mathrm{mp}=\mathrm{ti}, \mathrm{ab}, \mathrm{tx}, \mathrm{ct}]$

\section{PubMed}

(((Smoking OR "smoking cessation" OR "quit smoking" OR "stop smoking" OR cigarette OR "cigarette cessation" OR tobacco OR "tobacco cessation") AND (Smartphone OR "mobile phone" OR phone OR iPhone OR iOS OR Android OR "smart phone" OR "cell phone")) AND (App* OR application OR "mobile app*" OR "mobile software" OR "mobile program*" OR "smartphone app*" OR "smartphone software" OR "smartphone program*")) AND (Anxiety OR depression OR stress OR emotion* OR mental OR "mental health" OR "mental health wellbeing" OR "mental disorder*" OR "mental illness*" OR "psychiatric disorder*")

\section{Scopus}

( TITLE-ABS-KEY ( smoking OR "smoking cessation" OR "quit smoking" OR "stop smoking" OR cigarette OR "cigarette cessation" OR tobacco OR "tobacco cessation") AND TITLE-ABS-KEY ( smartphone OR "mobile phone" OR phone OR iphone OR ios OR android OR "smart phone" OR "cell phone") AND TITLE-ABS-KEY (app* OR application OR "mobile app*" OR "mobile software" OR "mobile program*" OR "smartphone app*" OR "smartphone software" OR "smartphone program*") AND TITLE-ABS-KEY (anxiety OR depression OR stress OR emotion* OR mental OR "mental health" OR "mental health wellbeing" OR "mental disorder*" OR "mental illness*" OR "psychiatric disorder*")) AND (LIMIT-TO (DOCTYPE, "ar") ) AND ( LIMIT-TO ( LANGUAGE, "English")) AND ( LIMIT-TO ( SRCTYPE, "j"))

\section{ACM Digital Library}

[[All: smoking] OR [All: "smoking cessation"] OR [All: "quit smoking"] OR [All: "stop smoking"] OR [All: cigarette] OR [All: "cigarette cessation"] OR [All: tobacco] OR [All: "tobacco cessation"]] AND [[All: smartphone] OR [All: "mobile phone"] OR [All: phone] OR [All: iphone] OR [All: ios] OR [All: android] OR [All: "smart phone"] OR [All: "cell phone"]] AND [[All: app*] OR [All: application] OR [All: "mobile app*"] OR [All: "mobile software"] OR [All: "mobile program*"] OR [All: "smartphone app*"] OR [All: "smartphone software"] OR [All: "smartphone program*"]] AND [[All: anxiety] OR [All: depression] OR [All: stress] OR [All: emotion*] OR [All: mental] OR [All: "mental health"] OR [All: "mental health wellbeing"] OR [All: "mental disorder*"] OR [All: "mental illness*"] OR [All: "psychiatric disorder*"]]

\section{IEEE Xplore}

1. ("All Metadata": "smoking cessation" OR "quit smoking" OR "stop smoking" OR "tobacco cessation") AND ("All Metadata":App^) AND ("All Metadata": Anxiety OR depression OR stress OR "mental health")

2. ("All Metadata":smok* OR "quit smoking" OR "stop smoking" OR "smoking cessation") AND ("All Metadata":App*) AND ("All Metadata": mobile) AND ("All Metadata": Anxiety OR depression OR stress OR menta

\section{Figures}




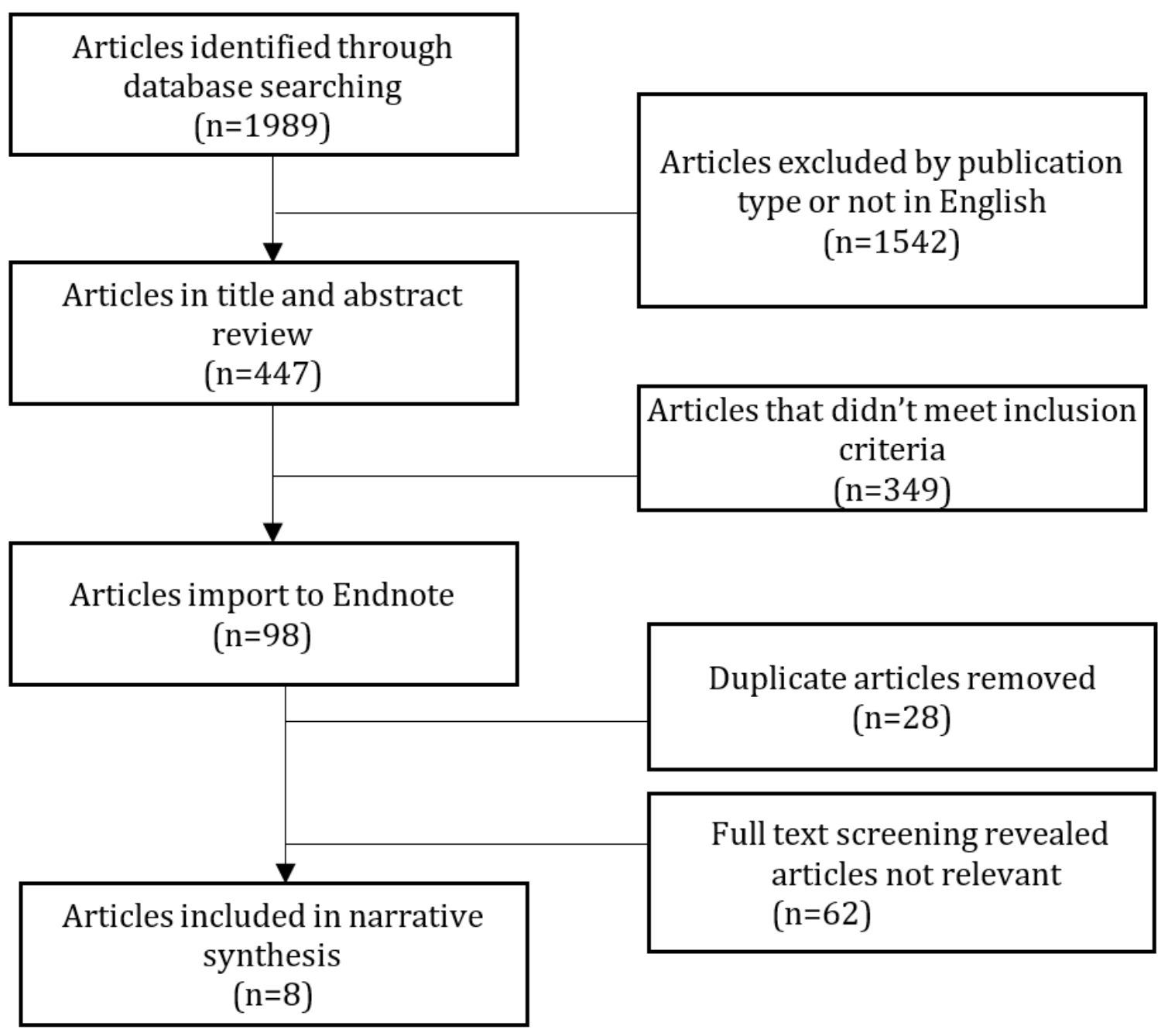

Figure 1

Flow Diagram of Study Selection 